\title{
Diagnostic Accuracy of Transvaginal Ultrasound in Perimenopausal and Postmenopausal Bleeding
}

(ORIGINAL ARTICLE)

\author{
Authors
}

\section{Santhosh Smitha', KM Asokan ${ }^{2}$}

${ }^{1}$ Associate Professor, Department of obstetrics and gynecology, Kannur Medical College, Anjarakandy ${ }^{2}$ Professor, Department of obstetrics and gynecology, Kannur Medical College, Anjarakandy

\section{ABSTRACT}

Aim: To study the endometrial pathology in patients with perimenopausal and postmenopausal bleeding by using transvaginal ultrasound, hysteroscopy and histopathology

To compare the sonographically measured endometrial thickness and morphology and hysteroscopic finding with histopathologic diagnosis in women with perimenopausal and postmenopausal bleeding

Materials and methods: Sample size is 50 and study was conducted between January 2008 and December 2014.

Inclusion criteria-perimenopausal women beyond 40 years and postmenopausal women,

Exclusion criteria - any use of hormone replacement therapy or progesterone therapy and patients with fibroids and adnexal mass. All patients underwent transvaginal ultrasound (TVS), hysteroscopy and endometrial biopsy in that order. Histopathological report was compared with TVS and hysteroscopic findings

Observations: Endometrial thickness measured by transvaginal ultrasound. Thickness above 4 mm is taken as abnormal. Endometrium studied by hysteroscopy and findings compared with transvaginal ultrasound and histopathological findings

Conclusions: TVS was complementary to hysteroscopy in the diagnosis of endometrial pathology. A $5 \mathrm{~mm}$ cutoff for endometrial thickness in postmenopausal women could reliably be ruled out endometrial pathology. Hysteroscopy was superior to TVS in the detection of focal pathology like polyps. Both TVS and hysteroscopy are complementary diagnostic methods to histopathology and could be accurately used to discriminate between normal and pathologic endometrial conditions in women with postmenopausal and perimenopausal bleeding.

Keywords: Perimenopausal bleeding, Postmenopausal bleeding, transvaginal ultrasound, hysteroscopy, histopathological examination, endometrial thickness, endometrial polyp

\section{INTRODUCTION}

Perimenopausal and postmenopausal bleeding are two important symptoms of aging women. In all cases an early diagnosis of carcinoma endometrium should be ruled out. Evaluation of perimenopausal bleeding is by transvaginal ultrasound and hysteroscopy. Diagnosis is by dilatation and curettage. In the present study reveals the significance of more non-invasive transvaginal ultrasound in evaluating perimenopausal and postmenopausal bleeding

\section{AIM OF STUDY}

1. To study the endometrial pathology in patients with perimenopausal and postmenopausal bleeding by using 
transvaginal ultrasound and histopathology.

2. To compare the sonographically measured endometrial thickness and morphology with histopathological diagnosis in women with perimenopausal and postmenopausal bleeding.

\section{MATERIALS AND METHODS}

Between January 2008 and December 2014, 50 women in the postmenopausal and perimenopausal age group (29 postmenopausal and 21 perimenopausal women) were enrolled in this prospective study at the department of Obstetrics and Gynecology Kannur Medical College. These patients were recruited from the gynecologic outpatient department for the evaluation of postmenopausal or perimenopausal bleeding according to a previously defined protocol. Approval and informed consent were obtained from the patients before they participated in the study. These patients first underwent a standard outpatient evaluation

Inclusion criteria-Perimenopausal women beyond 40 years and postmenopausal women,

Exclusion criteria-(1)Any use of hormone replacement therapy or progesterone therapy.

(2) Patients with fibroids and adnexal mass.

Transvaginal sonography was performed with the use of a $5 \mathrm{MHz}$ transducer. Endometrial thickness was measured as a double layer in the longitudinal plane at the widest point within the fundus and with the entire endocervical and endometrial stripe visible. In postmenopausal women $\leq 5 \mathrm{~mm}$ endometrial thickness was taken as a cut off for endometrial pathology. Endometrial ultrasound findings were classified as suggestive of atrophy, focal abnormality (benign or suspicious) and diffuse thickness (benign or suspicious).

Dilatation and curettage was done on all cases and specimen sent for histopathologic examination. Histopathologic diagnosis was performed in the department of Pathology at Kannur College. The histopathologic diagnosis was given as atrophy, normal, polyps (endometrial or endocervical), hyperplasia and endometrial carcinoma. Patients whose collected specimens were classified as scanty material were included in the atrophy group.Once the histopathologic diagnosis was obtained, it was compared with the ultrasonographic findings, and the sensitivity, specificity, positive predictive value and negative predictive values were calculated.

All procedures followed the ethical guidelines approved by the authorities in our institution.

\section{ANALYSIS OF RESULTS}

The results of this study which included a total of 50 patients, 29 postmenopausal $(58 \%)$ and 21 perimenopausal women $(42 \%)$ are summarized below.

Table 1 Age distribution of patients $(n=50)$

\begin{tabular}{|l|l|l|l|l|l|}
\hline Sl. No. & Age & PeM & $\%$ & PoM & $\%$ \\
\hline 1. & $40-49$ & 18 & 85.7 & 5 & 17.2 \\
\hline 2. & $50-59$ & 3 & 14.28 & 15 & 51.7 \\
\hline 3. & $60-69$ & 0 & 0 & 7 & 24.1 \\
\hline 4. & $>70$ & 0 & $0 \mathrm{~s}$ & 2 & 6.9 \\
\hline
\end{tabular}

PeM-perimenopausal

PoM-postmenopausal

Most of the perimenopausal women were between 40-49 years (85.7\%) and most of the postmenopausal women were between $50-59$ years $(51.7 \%)$. This mean age in the perimenopausal group was $45.71+1.44$ years and in the postmenopausal group was $56.1+2.83$ years. 
Table 2 Age distribution of patients $(n=50)$

PeM-perimenopausal

\begin{tabular}{|c|c|c|c|c|c|}
\hline Sl. No. & Parity & PeM & $\%$ & PoM & $\%$ \\
\hline 1. & Nulli & 0 & 0 & 1 & 3.4 \\
\hline 2. & P1 & 1 & 4.8 & 2 & 6.9 \\
\hline 3. & P2 & 15 & 71.4 & 6 & 20.7 \\
\hline 4. & P3 & 2 & 9.5 & 8 & 27.6 \\
\hline 5 & $>$ P4 & 3 & 14.3 & 12 & 41.4 \\
\hline & Total & 21 & 100 & 29 & 100 \\
\hline
\end{tabular}

PoM-postmenopausal

Majority of the womenwere multiparous $(41.4 \%)$ in the postmenopausal group. Only one woman was nulliparous $(3.4 \%)$. There were no nulliparous women in the perimenopausal group. Most of the women were para 2 and above.

Table 3 Age of menopause

\begin{tabular}{|l|c|c|c|}
\hline SL.No. & Age of menopause & No: & $\%$ \\
\hline 1 & $40-45$ years & 4 & 13.8 \\
\hline 2 & $46-50$ years & 16 & 55.2 \\
\hline 3 & 51-55 years & 9 & 31 \\
\hline & TOTAL & 29 & 100 \\
\hline
\end{tabular}

The mean age of menopause in the postmenopausal group was $49.2+1.1$ years and they had been postmenopausal for an average of $7+0.14$ years, ranging from 1 to 25 years.

Table 4 endometrial morphology $(n=50)$

\begin{tabular}{|l|l|c|c|c|c|c|c|}
\hline S1.No & Morphology & PeM & $\%$ & PoM & $\%$ & Total & $\%$ \\
\hline 1. & Normal & 2 & 9.52 & 4 & 13.8 & 6 & 12 \\
\hline 2. & Atrophic & 0 & 0 & 5 & 17.2 & 5 & 10 \\
\hline 3. & Benign diffuse & 14 & 66.7 & 17 & 58.6 & 31 & 62 \\
\hline 4. & Benign focal & 5 & 23.8 & 2 & 6.9 & 7 & 14 \\
\hline 5. & Suspicious & 0 & 0 & 1 & 3.5 & 1 & 2 \\
\hline & Total & 21 & 100 & 29 & 100 & 50 & 100 \\
\hline
\end{tabular}

The ultrasonographic findings were normal in $6(12 \%)$, suggestive of atrophy in $5(10 \%)$, benign focal abnormality in $7(14 \%)$, benign diffuse thickness in $31(62 \%)$ and suspicious pathology in one (2\%).

Table 5 Endometrial thickness

\begin{tabular}{|l|c|c|c|}
\hline Sl. No & Endometrial thickness & No. & $\%$ \\
\hline 1. & $<5 \mathrm{~mm}$ & 5 & 17.2 \\
\hline 2. & $>5 \mathrm{~mm}$ & 24 & 82.8 \\
\hline & Total & 29 & 100 \\
\hline
\end{tabular}

The mean endometrial thickness was $13.19+2.2 \mathrm{~mm}$ in perimenopausal women and $10.12+2.2 \mathrm{~mm}$ in postmenopausal women.In the postmenopausal women five had an endometrial thickness less than $5 \mathrm{~mm}$ $(17.2 \%)$.

Table 5 Histopathologic finding

\begin{tabular}{|l|l|c|c|c|c|c|c|}
\hline Sl. No. & Finding & PeM & $\%$ & PeM & $\%$ & Total & $\%$ \\
\hline 1. & Secretory & 2 & 9.5 & 0 & 0 & 2 & 4 \\
\hline 2. & Proliferative & 7 & 33.3 & 2 & 6.9 & 9 & 18 \\
\hline 3. & Atrophic & 0 & 0 & 5 & 17.2 & 5 & 10 \\
\hline
\end{tabular}




\begin{tabular}{|l|l|c|c|c|c|c|c|}
\hline 4. & Endometrial polyps & 6 & 28.6 & 10 & 34.5 & 16 & 32 \\
\hline 5. & Endocervical polyps & 1 & 4.8 & 3 & 10.4 & 4 & 8 \\
\hline 6. & Simple Hyperplasia & 5 & 23.8 & 7 & 24.1 & 12 & 24 \\
\hline 7. & Adenocarcinoma & 0 & 0 & 2 & 6.9 & 2 & 4 \\
\hline & Total & 21 & 100 & 29 & 100 & 50 & 100 \\
\hline
\end{tabular}

Histologic findings consisted of normal endometrium in 11 (22\%), atrophic endometrium in 5 (10\%), benign polyps in 20 (40\%), simple hyperplasia in $12(24 \%)$ and adenocarcinoma in $2(4 \%)$. Both cases of adenocarcinoma were detected in postmenopausal women.

Table 6 comparison between ultrasonography and histopathologic findings

\begin{tabular}{|l|c|c|c|c|c|}
\hline Sl No & Finding & TVS & $\%$ & Histopathology & $\%$ \\
\hline 1. & Normal & 6 & 12 & 11 & 22 \\
\hline 2. & Atrophic & 5 & 10 & 5 & 10 \\
\hline 3. & Benign focal & 7 & 14 & 20 & 40 \\
\hline 4. & Benign diffuse & 31 & 62 & 12 & 24 \\
\hline 5. & Suspicious & 1 & 2 & 2 & 4 \\
\hline & Total & 50 & 100 & 50 & 100 \\
\hline
\end{tabular}

Table 7 Comparison between ET and Histopathology

\begin{tabular}{|l|c|c|c|c|c|c|c|c|c|}
\hline ET & Normal & $\%$ & Atrophic & $\%$ & Benign & $\%$ & Malignant & $\%$ & Total \\
\hline$<5 \mathrm{~mm}$ & 0 & 0 & 5 & 100 & 0 & 0 & 0 & 0 & 5 \\
\hline$>5 \mathrm{~mm}$ & 2 & 8.3 & 0 & 0 & 20 & 83.3 & 2 & 8.3 & 24 \\
\hline
\end{tabular}

ET-endometrial thickness

\section{DISCUSSION}

Most commonly performed diagnostic method in perimenopausal and postmenopausal bleeding is dilatation and curettage which is an inpatient procedure ${ }^{1,2}$ Prior reports suggest that in $60 \%$ women submitted for curettage, less than half of the endometrial cavity was sampled with the curette $^{3}$ Furthermore, focal benign abnormalities are usually missed by this procedure and may be a source of continued or recurrent bleeding Recent reports showed that the combined assessment of endometrial thickness with some morphological parameters improve the diagnostic accuracy of transvaginal sonography ${ }^{1}$

Some morphological parameters improve the diagnostic accuracy of transvaginal sonography ${ }^{4}$. Several studies have assessed the accuracy of transvaginal ultrasonography in evaluating the endometrium for malignancy ${ }^{5,6}$ Transvaginal ultrasonography is a highly sensitive test for detecting endometrial disease, but carries a false negative rate of $8 \%$ for endometrial carcinoma ${ }^{7}$.
Recent reports showed that the combined assessment of endometrial thickness with some morphological parameters improve the diagnostic accuracy of transvaginal sonography ${ }^{8}$. In the present study, transvaginal sonography was performed in all the patients. Findings were classified according to endometrial thickness and morphological criteria in postmenopausal women and according to morphological criteria in perimenopausal women. Endometrial abnormalities by TVS showed a sensitivity of $88.2 \%$ and a specificity of $43.8 \%$ with a positive predictive value of $76.9 \%$ and a negative predictive value of $63.6 \%$. In postmenopausal women the sensitivity was $81.8 \%$ and specificity was $71.4 \%$ with a positive predictive value of $90 \%$ and a negative predictive value of $55.6 \%$. In perimenopausal women the sensitivity was $100 \%$ and specificity was $22.2 \%$ with a positive predictive value of $63.16 \%$ and a negative predictive value of $100 \%$.Endometrial thickness alone had a sensitivity of $100 \%$ and a specificity 
of $71.4 \%$ with a positive predictive value of $91.67 \%$ and a negative predictive value of $100 \%$ in postmenopausal women.

Saidi $\mathrm{MH}^{9}$ et al compared transvaginal sonography, sonohysterography and hysteroscopy in the evaluation of abnormal uterine bleeding in 68 perimenopausal women over 40years. Transvaginal ultrasonography revealed a sensitivity and specificity of $95 \%$ and $65 \%$ respectively.In perimenopausal women in the present study, the sensitivity was $100 \%$ and specificity was $22.2 \%$ with a positive predictive value of $63.16 \%$ and a negative predictive value of $100 \%$ by transvaginal ultrasound

Table 8 Accuracy of TVS in perimenopausal women

\begin{tabular}{|l|c|c|c|}
\hline Study & Total No. & Sensitivity & Specificity \\
\hline Saidi et al & 68 & 95 & 65 \\
\hline Present study & 21 & 100 & 22.2 \\
\hline
\end{tabular}

In postmenopausal women endometrial thickness $5 \mathrm{~mm}$ was taken as cut off for endometrial pathology. Haller $\mathrm{H}^{10}$ et al compared the endometrial thickness determined by transvaginal sonography with histologic findings obtained by dilatation and curettage. Using a cut-off limit for endometrial pathology of $5 \mathrm{~mm}$. the sensitivity was $95.8 \%$ the specificity was $45.5 \%$ positive predictive value was $71.9 \%$ and negative predictive value was $88.2 \%$

In the present study, endometrial thickness alone had a sensitivity of $100 \%$ and a specificity of $71.4 \%$ with a positive predictive value of $91.6 \%$ and a negative predictive value of $100 \%$ in postmenopausal women. All women with endometrial thickness $<5 \mathrm{~mm}$ were found to have atrophic endometrium subsequently.

Table 9 Accuracy of endometrial thickness in postmenopausal women

\begin{tabular}{|l|c|c|c|c|c|}
\hline Study & $\begin{array}{c}\text { Total } \\
\text { No. }\end{array}$ & Sensitivity & Specificity & $\begin{array}{c}\text { Positive } \\
\text { predictive value }\end{array}$ & $\begin{array}{c}\text { Negative } \\
\text { predictive value }\end{array}$ \\
\hline Haller H et al & 80 & 95.8 & 45.5 & 71.9 & 88.2 \\
\hline Present study & 29 & 100 & 71.4 & 91.67 & 100 \\
\hline
\end{tabular}

SouzaR ${ }^{11}$ et.al determined the diagnostic value of transvaginal ultrasonography and histopathology in 88 women with postmenopausal bleeding. According to morphological criteria ultrasonography revealed a sensitivity, specificity, positive predictive value and negative predictive value of $79.5 \%, 88 \%, 92.1 \%$ and $71 \%$ respectively.
In the postmenopausal women in the present study, TVS morphology has a sensitivity of $81.8 \%$ and specificity of $71.4 \%$ with a positive predictive value of $90 \%$ and a negative predictive value of $55.6 \%$. Thus transvaginal ultrasonography revealed a good sensitivity in picking up endometrial pathology

Table 10 Accuracy of endometrial morphology in postmenopausal women

\begin{tabular}{|l|c|c|c|c|c|}
\hline Study & $\begin{array}{c}\text { Total } \\
\text { No. }\end{array}$ & Sensitivity & Specificity & $\begin{array}{c}\text { Positive predictive } \\
\text { value }\end{array}$ & $\begin{array}{c}\text { Negative } \\
\text { predictive value }\end{array}$ \\
\hline Souza R et al & 88 & 79.5 & 88 & 92 & 71 \\
\hline Present study & 29 & 81.8 & 71.4 & 90 & 55.6 \\
\hline
\end{tabular}

\section{CONCLUSION}

A total of 50 patients in the perimenopausal and postmenopausal age group were selected for transvaginal ultrasonography followed by hysteroscopy for the evaluation of abnormal uterine bleeding in this study. Majority of patients were in the 40-49 age group in perimenopausal women and in the 50-59 age group in the postmenopausal women. 
In the detection of endometrial abnormalities transvaginal ultrasound showed a sensitivity of $88.2 \%$ and a specificity of $43.75 \%$ with a positive predictive value of $76.9 \%$ and a negative predictive value of $63.63 \%$. A $5 \mathrm{~mm}$ cut off for endometrial thickness in postmenopausal women could reliably be ruled out endometrial pathology.

\section{REFERENCE}

1. Weber G,Merz E, Bahlmann F, Rosch B. Evaluation of different transvaginal parameters in women with postmenopausal bleeding. Ultrasound ObstetGynaecol 1998; 12:265-70

2. Buyuk E, Durmusoglu F, Erenus M, KarakocB.Endometrial disease diagnosed by transvaginal ultrasound and dilatation and curettage, ActaObstetGynecol Scand1999;78:419-22

3. Stock RG, Kanbur A. prehysterectomy curettage. ObstetGynecol 1975; 45:537-41

4. Bakour SH, DwarakananthLH.the diagnostic accuracy of ultrasound in predicting endometrial hyperplasia and cancer in postmenopausal bleeding:ActaObstetGynecolScand 2009 ;78:448-51

5. Haller H,Matejsic N, Rukavina B, Krasevic M, Rupcic S, Mozetic Transvaginal sonography and hysteroscopy in women with postmenopausal bleeding. Int $\mathrm{J}$ GynaecolObstet 1996;54:155-9

6. LoverroG,BettochiS,CormioG,NicolardiV, GrecoP,Vimercarti A et al.Transvaginal sonography and hysteroscopy in postmenopausal uterine bleeding, Maturitas 1999;33:139-44

7. Smith Bindman R, Kerlikowske K, Feldstein VA etal.Endovaginal ultrasound to exclude endometrial cancer and other abnormalities. J Am Med Assocn 1998;280:1510-17

8. Granberg S, Wiklan M. Endometrial thickness as measured by transvaginal ultrsonography for identifying endometrial abnormality.Am J ObstetGynecol 2011;164:47-52

9. Saidi $\mathrm{MH}$, Bigrigg MA, Browning JJ, Brookes ST, Smith PA.A randomized controlled trial comparing transvaginal ultrasound outpatient hysteroscopy and endometrial biopsy with inpatient hysteroscopy and curettage. $\mathrm{Br} \mathrm{J}$ ObstetGynecol 1999;106:1259-64

10. Haller H, O'Connor H,BaskettT, Davies A ,Mohammed H, Magos AL. Hysteroscopy in women with uterine bleeding on hormone replacement therapy:a comparison with postmenopausal bleeding.FertSteril 1996;65:1145-50

11. Souza R, Serden SP: Hysteroscopic findings after unsuccessful dilatation and curettage for abnormal uterine bleeding.Am J ObstetGynecol 1998;158:1354-57 